\title{
Phytochemical Screening, Anti-Oxidant Potential and Anti- Ulcer Activity of Leucas diffusa Plant Extract
}

\author{
D. Jagadeesh ${ }^{* 1}$, Y. Anil Kumar², N. Tulasi Uma Rani ${ }^{2}$, A Prathyusha ${ }^{2}$, Shaik Abdul Mahaboobsubhani ${ }^{1}$ \\ ${ }^{1}$ Student, Department of Pharmacology, Hindu College of Pharmacy, Amaravthi Road, Guntur, A.P.-522007
}

${ }^{2}$ Assistant Professor, Department of Pharmacology, Hindu College of Pharmacy, Amaravthi Road, Guntur, A.P.-522007

\begin{abstract}
Leucas diffusa (lamiaceae) a branched herb collected from the Guntur region, A.P. India. Phytochemical studies of Leucas diffusa, methanolic fraction subjected to column chromatography and estimation of total flavanoid content and to evaluate antioxidant potential and anti-ulcer activity of methanolic extract of Leucas diffusa. The plant powder was subjected to continuous hot extraction in Soxhlet Apparatus \& extracted successively with n-hexane, ethyl acetate and methanol solvents. The extracts prepared were tested for the type of chemical constituents present by known qualitative tests. Total flavanoid content of methanolic and ethylacetate extract of Leucas diffusa were done. In vitro Antioxidant activity of methanolic extract was evaluated using hydroxyl radical, reducing power \& hydrogen peroxide scavenging abilities. Antiulcer activitiy of methanolic extract was evaluated through pylorus ligation method and ethanol induced ulcer models. Statistical analysis was performed by one-way analysis of variance (ANOVA) followed by the tukey's test for multiple comparisons. Our findings suggest that methanolic extract of whole plant Leucas diffusa have got profound antioxidant effect and showed significant anti-ulcer activity at higher dose.
\end{abstract}

Keywords: Leucas diffusa; Antioxidant; Flavanoid; anti-ulcer activity.

Article Info: Received 11 July 2019; $\quad$ Review Completed 21 Aug 2019; $\quad$ Accepted 26 Aug 2019; Available online 15 Oct 2019

Jagadeesh D, Anil Kumar Y, Uma Rani NT, Prathyusha A, Mahaboobsubhani SA, Phytochemical Screening, Anti-Oxidant Potential and Anti- Ulcer Activity of Leucas diffusa Plant Extract, Journal of Drug Delivery and Therapeutics. 2019; 9(5s):65-72 http://dx.doi.org/10.22270/jddt.v9i5-s.3647

*Address for Correspondence:

D. Jagadeesh, Student, Department of Pharmacology, Hindu College of Pharmacy, Amaravthi Road, Guntur, A.P.-522007

\section{INTRODUCTION}

Plants are one of the most important sources of medicine. Today the large number of drugs in use is derived from plants, such as morphine from Papaver somniferum, Aswagandha from Withania somnifera, Ephedrine from Ephedra vulgaris, Atropine from Atropa belladonna, Reserpine from Rauwolfial serpentine etc. The medicinal plants are rich in secondary metabolites (which are potential sources of drugs) and essential oils of therapeutic importance. The important advantages claimed for therapeutic uses of medicinal plants in various ailments are because of their safety, besides being economical, effective and their easy availability. Because of these advantages the medicinal plants have been widely used by the traditional medical practitioners in their day to day practice. Plants have been used for health and medicinal purpose since thousand years. They are one of the rich and important sources of medicine since human civilization. Now a day, it is preferred to use plant based medicines over synthetic medication for the treatment of different diseases because of their safety and cost effectiveness. Herbal medicines are particularly used by traditional practitioners since ancient times, inspite of their poor scientific data. Moreover continues exposure to stressful conditions generates free radicals, which may over power the inbuilt protective mechanisms and cause tissue damage. These are reports that plants possessing free radical scavenging activity are known to have organ protective effect. Many scientists are reported that, flowers and green leaves of the plant are useful as medicines.[1,2]

Natural antioxidants present in the plants scavenge harmful free radicals from our body. Free radical reactions have been implicated in the pathology of numerous diseases[3]. It is possible to reduce the risk of chronic diseases \& prevent disease progression by either enhancing the body's natural antioxidant defences or by supplementing with proven dietary antioxidants[4]. Synthetic antioxidants like ascorbic acid, butylhydroxyanisole (BHA) and butylhydroxytoulene (BHT) are commonly used in foods have their potential health risks \& toxicity. Thus the need for alternative sources of antioxidant is paramount \& the search for natural antioxidant, especially of plant origin has received much attention[5]. Plant polyphenolic compounds, such as flavanoids are described as scavengers of ROS. Most sources of natural antioxidant originate from plant material. It has 
been also reported that reactive oxygen species (ROS) participate in the process of peptic ulcers. In addition to their role in acute inflammation, Several factors are recognized to contribute to the pathogenesis of peptic ulcers including an overgeneration of reactive oxygen species (ROS). Therefore, compounds that have scavenging activities toward these radicals may be expected to have therapeutic potentials for several antiulcerogenic activities. [5]

Most clinically important medicines belong to steroidal or non-steroidal anti-inflammatory chemical therapeutics for treatment of inflammation-related disease. Though these have potent activity, long term administration is required for treatment of chronic disease. Furthermore, these drugs have various and severe adverse effects. Therefore, naturally originated agents with very little side-effects are required to substitute clinical therapeutics. [6]

Medicinal plants are believed to be an important source of new chemical substances with potential therapeutic effects. Plants of genus Leucas are widely used in traditional medicine to cure many diseases such as cough, cold, diarrhoea and inflammatory skin disorder. The genus Leucas comprises of about 2,500 species. The highest species diversity has been found in East Africa. In India 43 species are available. [7]

Leucas diffusa (family-lamiaceae) is an annual herb found throughout India as a weed in cultivated fields, wastelands and roadsides. Leaves are opposite, oval shaped with tapered end. Whitish hairs are generally present on the outer surface of upper lip of the corolla. There is no scientific report published indicating utility of this plant material. The aim of the present work was to evaluate the antioxidant potential and anti-ulcer activity of Leucas diffusa methanolic extract (LDME) using hydroxyl radical scavenging activity, reducing power activity \& hydrogen peroxide scavenging activity and total flavanoid content to support the pharmacological and Phytochemical investigation of this plant.

\section{MATERIALS AND METHODS}

Plant material

Leucas diffusa (lamiaceae), a branched herb collected from the Guntur region, A.P. India

\section{Animals}

Wistar Albino rats (150-200) of both sexes were obtained \& were maintained in a controlled environment at $22 \pm 2 \circ \mathrm{C}$ and $55 \pm 10 \%$ humidity with $12 \mathrm{~h}$ light-dark cycle and fed with standard pellet food and water ad libitum. The experimental design \& research plan along with animals handling and disposal procedure were placed before the institutional ethics committee.

\section{extract preparation:}

The whole plant was dried in shade, separated and made to dry powder. A weighed quantity (500gm) of the powder was subjected to continuous hot extraction in Soxhlet Apparatus \& extracted successively with $n$-hexane, ethyl acetate and methanol solvents. The methanolic extract yielded a brown sticky mass weighing 19.2g.[8]

\section{Preliminary chemical characterization of the extract Leucas diffusa:}

The extracts prepared were tested for the type of chemical constituents present by known qualitative tests.

\section{Determination of Total Flavanoid content:}

Total flavanoid contents were estimated based on the formation of a complex flavanoid-aluminium. Apigenin was used to make the calibration curve $[25,50,100,150,200$ $\mu \mathrm{g} / \mathrm{ml}$ in $99.9 \%$ ethanol $(\mathrm{v} / \mathrm{v})]$. The standard solutions or extracts $(0.5 \mathrm{ml})$ were mixed with $1.5 \mathrm{ml} 95 \%$ methanol (v/v), $0.1 \mathrm{ml} 10 \% \mathrm{AlCl} 3,0.1 \mathrm{ml}$ of $1 \mathrm{~mol} / \mathrm{l}$ sodium acetate and $2.8 \mathrm{ml} \mathrm{H} 2 \mathrm{O} 2$. Blank contains $10 \% \mathrm{AlCl} 3$ and the same volume of distilled water. After $30 \mathrm{~min}$, the absorbance of the reaction mixture was measured at $415 \mathrm{~nm}$ using UVVisible spectrophotometer. All determinations were done in triplicate and values were calculated from calibration curve obtained from apigenin and total flavonoid content is expressed as $\mu \mathrm{g}$ of Apigenin equivalents $(\mathrm{AE}) / \mathrm{mg}$ of extract[9].

\section{Evaluation of in vitro antioxidant activity}

\section{Hydroxyl radical-scavenging activity:}

$1 \mathrm{ml}$ of the final reaction solution consisted of aliquots $(500$ $\mu \mathrm{l})$ of various concentrations of the extract, $1 \mathrm{mM} \mathrm{FeCl} 3,1$ mM EDTA, $20 \mathrm{mM} \mathrm{H2O2,} 1 \mathrm{mM}$ L-ascorbic acid, and $30 \mathrm{mM}$ deoxyribose in potassium phosphate buffer $(\mathrm{pH} 7.4)$. The reaction mixture was incubated for $1 \mathrm{~h}$ at $37^{\circ} \mathrm{C}$, and further heated in a boiling water bath for $15 \mathrm{~min}$ after addition of 1 $\mathrm{ml}$ of $2.8 \%(\mathrm{w} / \mathrm{v}) \mathrm{TCA}$ and $1 \mathrm{ml}$ of $1 \%(\mathrm{w} / \mathrm{w}) 2$-TBA. The color development was measured of $532 \mathrm{~nm}$ against a blank containing phosphate buffer. The ability of the plant extract to scavenge hydroxy radical was calculated by the equation: Hydroxy radical scavenging activity $=\{($ Abs 1- Abs 2)/ $($ Abs0) $\} \times 100$ Where; Abs1 is the absorbance of extract; Abs 2 is the absorbance of ascorbic acid; Abs 0 is the absorbance of control [10]

\section{Reducing power activity:}

Different concentrations of extracts were mixed with $2.5 \mathrm{ml}$ of phosphate buffer (200 mM, pH 6.6) and $2.5 \mathrm{ml}$ of $1 \%$ potassium ferricyanide. The mixtures were incubated for $20 \mathrm{~min}$ at $50^{\circ} \mathrm{C}$. After incubation, $2.5 \mathrm{ml}$ of $10 \%$ trichloroacetic acid were added to the mixtures, followed by centrifugation at $3000 \mathrm{rpm}$ for $10 \mathrm{~min}$. The upper layer $(5$ $\mathrm{ml}$ ) was mixed with $5 \mathrm{ml}$ of distilled water and $1 \mathrm{ml}$ of $0.1 \%$ ferric chloride and the absorbance of the resultant solution were measured at $700 \mathrm{~nm}$. Increased absorbance of the reaction mixture indicated higher reducing power of the plant extract.[11]

\section{Hydrogen peroxide-scavenging activity:}

The extract was dissolved in $3.4 \mathrm{ml}$ of $0.1 \mathrm{M}$ phosphate buffer (pH 7.4) and mixed with $600 \mu \mathrm{l}$ of $43 \mathrm{mM}$ solution of hydrogen peroxide. The absorbance value (at $230 \mathrm{~nm}$ ) of the reaction mixture was recorded at $10 \mathrm{~min}$ intervals between zero and $40 \mathrm{~min}$. for each concentration, a separate blank sample was used for background substraction. The amount of hydrogen peroxide radical inhibited by the extract was calculated using the following equation: H2O2 radical scavenging activity $=\{($ Abs control - Abs sample $) /($ Abs control) $\} \times 100$ Where; Abs control - absorbance of H2O2 radical + methanol; Abssample - absorbance of $\mathrm{H} 2 \mathrm{O} 2$ radical +sample extract or standard.[12]

\section{Pylorus ligation in rat:}

\section{Procedure:}

Female Wistar rats weighing 150-170 g are starved for 48 hours having access to drinking water ad libitum. During this time they are housed single in cages in prevent coprophagy. Six animals are used per dose and as control groups. Under mild ether anaesthesia an incision is made at the abdominal 
midline. The pylorus is closed by using small nylon the higher supervision is required to avoid he damage of blood vessels inside the pylorus region. Grasping the stomach with instruments is to be meticulously avoided; else ulceration will invariably develop at such points. The abdominal wall are sutured through surgical procedure. The test sample are administrated through oral ingestion or injected subcutaneous route. The animals are placed for 19 hours in a suitable plastic container. Afterwards, these animals are sacrificed in $\mathrm{CO} 2$ anaesthesia. The abdomen is re ligated and a ligature is placed above the esophagus region and closer to the diaphragm area. The stomach is replaced to a watch glass and the materials are collected in to a centrifugal tube. Above the longer curvature the stomach fully opened and pinned between a cork plates. The mucosal layer is observed with the help of a stereomicroscope.[13]

\section{Ethanol induced gastric ulcer}

Albino Wistar rats of both sex having (150-200g) are divided in to 5 groups of 6 animals each. They are housed in individual cages and fasted for $24 \mathrm{hrs}$ allowing free access to drinking water. Care being taken to avoid coprophagy. Ulceration was induced in 36 hours without feeding the rats by the administration of $80 \%$ ethanol orally in a dose of $1 \mathrm{ml}$ for each rat. Test and Standard is given each dose level of rat, one hour before the ethanol administration. After two hours of ethanol administration, animals will be sacrificed by $\mathrm{CO} 2$ poisoning. The stomach is dissected out, opened along the greater curvature and the contents are drained in a centrifuge tube and were centrifuged at 1000rpm for 10 minutes and the volume is noted. The $\mathrm{pH}$ of the gastric juice is recorded by using a $\mathrm{pH}$ meter. Then the contents are subjected to analysis for free and total acidity. The stomachs are then washed with running water to see for ulcers in the glandular portion of the stomach. The numbers of ulcers per stomach are noted and severity of the ulcers scored microscopically with the help of $10 x$ lens.

\section{RESULTS:}

The identified chemical constituents in the Lucas diffusa were listed in the table no 1.

Table:1 Qualitative chemical tests for phytoconstituents

\begin{tabular}{|l|l|l|l|l|}
\hline S.No & Name of the test & Hexane extract & Ethyl acetate extract & Methanolic extract \\
\hline 1 & Test for terpenoids & + & + & + \\
\hline 2 & Test for steroids & - & + & + \\
\hline 3 & Test for saponins & - & - & + \\
\hline 4 & Test for alkaloids & - & - & + \\
\hline 5 & Testfor carbohydrates & - & - & + \\
\hline 6 & Tests for flavanoids & + & + & + \\
\hline 7 & Tests for tannins & - & + & + \\
\hline 8 & Tests for glycosides & - & + & + \\
\hline
\end{tabular}

\section{IN-VITRO ANTIOXIDANT ACTIVITY}

\section{Hydroxyl radical scavenging activity}

LDME showed hydroxyl radical scavenging activity with about $95.80 \%$ and $98.88 \%$ at concentration of $5 \mu \mathrm{g} / \mathrm{ml}$, $500 \mu \mathrm{g} / \mathrm{ml}$.A concentration dependent inhibition against hydroxyl radical induced deoxyribose degradation was observed in the de oxy ribose assay. Because the LD was high in its flavonoid content, its antioxidant compounds may well act as antioxidant and scavenge hydroxyl radical generated from the Fenton reagent (Table 2).

Table 2. Hydroxyl radical scavenging activity of LDME

\begin{tabular}{|l|l|l|}
\hline Conc $(\boldsymbol{\mu g} / \mathbf{m l})$ & $\begin{array}{l}\text { DMSO inhibition } \\
\mathbf{\%}\end{array}$ & LDME \% \\
\hline 5 & 96.43 & 95.80 \\
\hline 500 & 99.63 & 98.88 \\
\hline
\end{tabular}

All the values are means of three independent determinations, $n=3$, analyzed in triplicate.

\section{Reducing power activity}

At concentration $5 \mu \mathrm{g} / \mathrm{ml}$ and $500 \mu \mathrm{g} / \mathrm{ml}$ Ascorbic Acid (Reference) and MELD showed absorbance with about 0.382-0.509 and 0.019-0.995 respectively (Table 3).

Table3.Reducing power activity of methanolic plant extract of Leucas diffusa

\begin{tabular}{|l|l|l|}
\hline $\begin{array}{l}\text { Conc } \\
(\boldsymbol{\mu g} / \mathbf{m l})\end{array}$ & $\begin{array}{l}\text { Ascorbic acid } \\
\text { (absorbance) }\end{array}$ & $\begin{array}{l}\text { LDME } \\
\text { (absorbance) }\end{array}$ \\
\hline 5 & 0.382 & 0.019 \\
\hline 500 & 0.509 & 0.995 \\
\hline
\end{tabular}

All the values are means of three independent determinations, $\mathrm{n}=3$, analyzed in triplicate.
Thus LDME exhibited reducing activity \& might be due to hydrogen donating ability.

\section{Hydrogen peroxide-scavenging activity}

The hydroxyl free radical in the cells can easily cross cell membranes and react with most biomolecules causes tissue damage, cancer and cell death. Thus, removal of hydroxyl free radical is necessary in to protect life. Scavenging effect of various fractions with ascorbic acid showed that Ascorbic Acid ( $5 \mu \mathrm{g}$ to $500 \mu \mathrm{g})$ and LDME $(5 \mu \mathrm{g}$ and $500 \mu \mathrm{g})$ as reference compound was shown to be $74.75 \%-81.04 \%$ and $29.45 \%$ 78.86\% (Table 4).

Table 4.Shows hydrogen peroxide scavenging activity of Leucas diffusa

\begin{tabular}{|l|l|l|}
\hline Conc ( $\mu \mathrm{g} / \mathrm{ml})$ & $\begin{array}{l}\text { Ascorbic acid } \\
\text { inhibition \% }\end{array}$ & LDME\% \\
\hline 5 & $74.75 \%$ & $62.06 \%$ \\
\hline 500 & $81.04 \%$ & $73.12 \%$ \\
\hline
\end{tabular}
determinations, $n=3$, analyzed in triplicate

All the values are represented as mean \pm SD, when analysed with paired t test using Graph pad prism. 
Figure 3 Calibration curve of Ascorbic acid

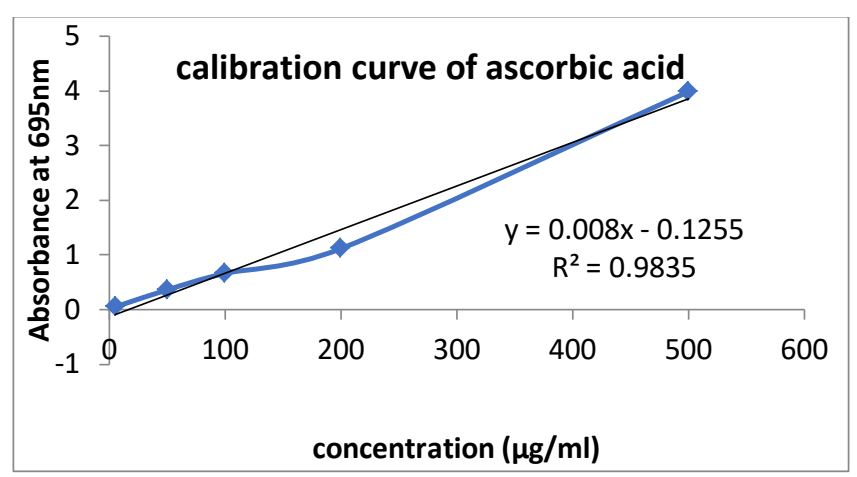

Based on the results obtained LDME showed antioxidant and free radical scavenging activity not remarkably different than reference compound Ascorbic Acid and major antioxidative component seems to contain flavonoids. Therefore, it can be concluded that the LDME could be considered for prevention and treatment of human diseases and its complications as potent antioxidant.

\section{IN-VIVO ANTI ULCER ACTIVITY}

\section{Pylorus ligation method}

The gastric parameters like gastric $\mathrm{pH}$, total acidity and ulcer index was calculated and given in the table 6

Table 5: Gastric parameters observed in pylorus ligation method

\begin{tabular}{|l|l|l|l|}
\hline Group & Gastric $\mathbf{~ H ~}$ & Total Acidity & Ulcer Index \\
\hline Normal & $2.76 \pm 0.113$ & $36 \pm 1.15$ & $1.697 \pm 0.01667$ \\
\hline Control & $2.19 \pm 0.0457$ & $42 \pm 0.856$ & $10.31 \pm 0.02108$ \\
\hline Standard & $3.8 \pm 0.105$ & $26.2 \pm 1.85$ & $0 \pm 0$ \\
\hline LDME $100 \mathrm{mg} / \mathbf{k g}$ & $2.58 \pm 0.122^{\mathrm{ns}}$ & $40.5 \pm 0.764^{\mathrm{ns}}$ & $10.26 \pm 0.02108^{*}$ \\
\hline LDME $200 \mathrm{mg} / \mathrm{kg}$ & $3.53 \pm 0.0233^{* * *}$ & $36.7 \pm 0.803^{\mathrm{ns}}$ & $5.08 \pm 0.02236^{* * *}$ \\
\hline LDME $400 \mathrm{mg} / \mathbf{k g}$ & $3.6 \pm 0.123^{* * *}$ & $37.8 \pm 0.982^{*}$ & $3.8709 \pm 0.3425^{* * *}$ \\
\hline
\end{tabular}

Values were expressed as Mean \pm SEM; $\mathrm{n}=6$ and are significant when analyzed by one way ANOVA with Tukey's post hoc test. ns $=$ not significant, ${ }^{*} \mathrm{P}<0.05,{ }^{* *} \mathrm{P}<0.01$ and ${ }^{* * *} \mathrm{P}<0.001$ when compared with Control group.

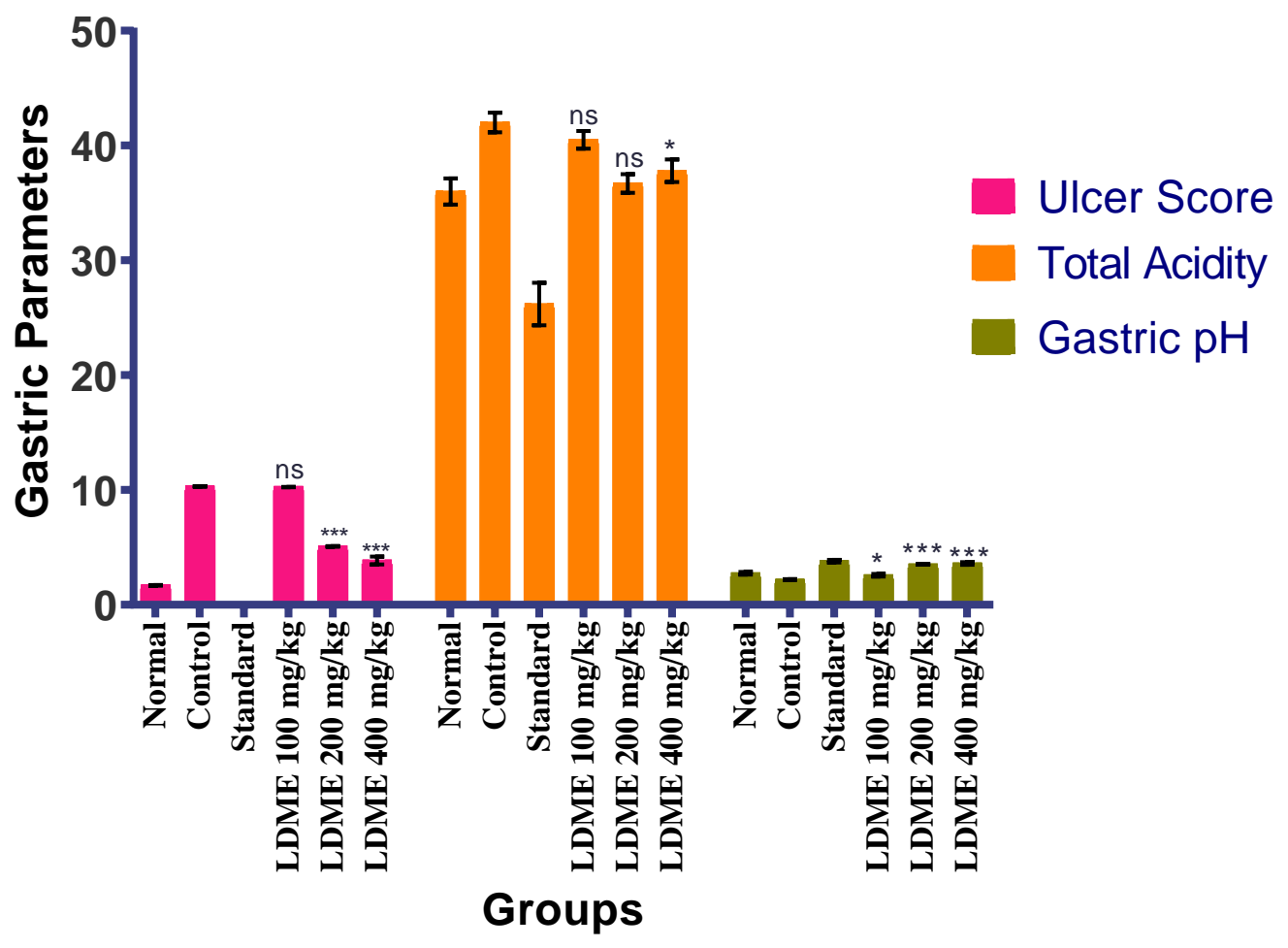

Figure 4: Graph representing gastric parameters pylorus ligation induced ulcers 


\section{Ethanol induced ulcers:}

The gastric parameters like gastric $\mathrm{pH}$, total acidity and ulcer index was calculated and given in the table 7 .

Table 6: Gastric parameters observed in ethanol induced ulcers

\begin{tabular}{|l|l|l|l|}
\hline Group & Gastric $\mathbf{~ H H}$ & Total Acidity & Ulcer Index \\
\hline Normal & $2.72 \pm 0.133$ & $28.8 \pm 0.601$ & $0 \pm 0$ \\
\hline Control & $2 \pm 0.0308$ & $36.7 \pm 1.2$ & $10.25 \pm 0.02582$ \\
\hline Standard & $3.63 \pm 0.0448$ & $26.2 \pm 1.85$ & $0 \pm 0$ \\
\hline LDME $100 \mathbf{~ m g} / \mathbf{k g}$ & $2.41 \pm 0.0855^{* *}$ & $40 \pm 0.73^{\mathrm{ns}}$ & $6.817 \pm 0.02108^{* * *}$ \\
\hline LDME $\mathbf{2 0 0} \mathbf{~ m g / k g}$ & $3.07 \pm 0.0253^{* * *}$ & $35.2 \pm 1.35^{\mathrm{ns}}$ & $6.793 \pm 0.01667^{* * *}$ \\
\hline LDME $400 \mathbf{~ m g / k g}$ & $3.5 \pm 0.0562^{* * *}$ & $29.8 \pm 0.601^{* *}$ & $3.383 \pm 0.02108^{* * *}$ \\
\hline
\end{tabular}

Values were expressed as Mean \pm SEM; $n=6$ and are significant when analyzed by one way ANOVA with Tukey's post hoc test. $n s$ $=$ not significant, ${ }^{*} \mathrm{P}<0.05,{ }^{* *} \mathrm{P}<0.01$ and ${ }^{* * *} \mathrm{P}<0.001$ when compared with Control group.

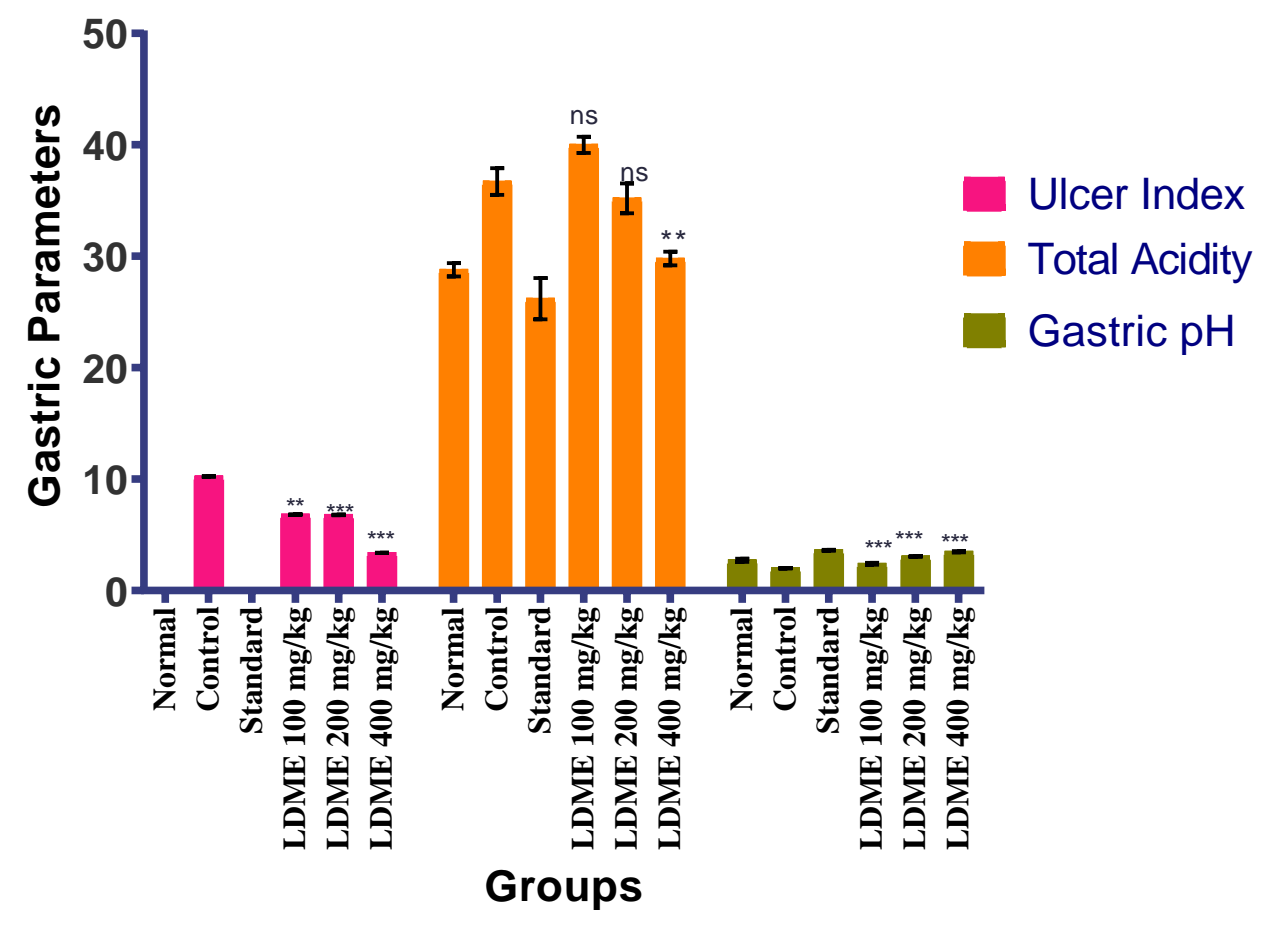

Figure 5: Graph representing gastric parameters ethanol induced ulcers 
Opened stomach showing ulcers:

Pylorus ligation method:

Normal

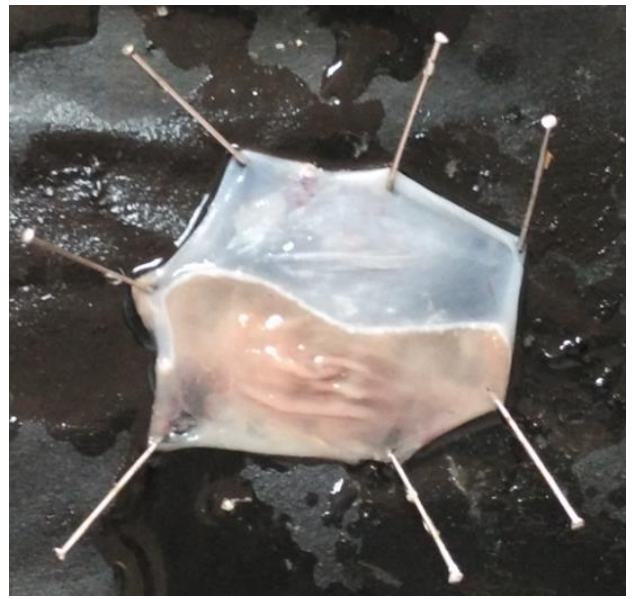

Standard

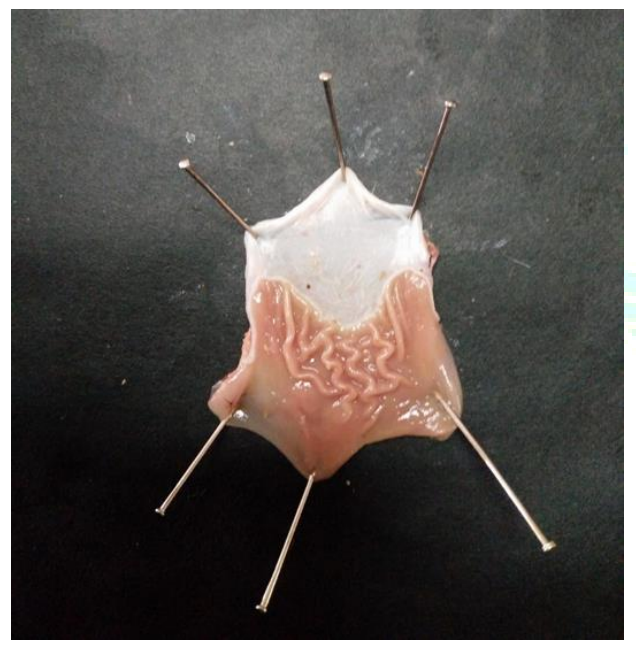

LDME 200

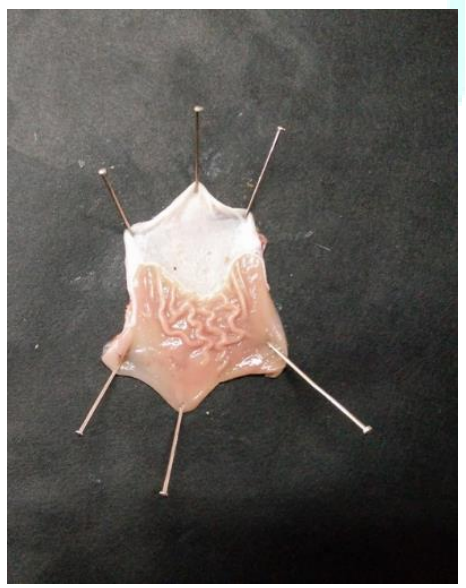

Control

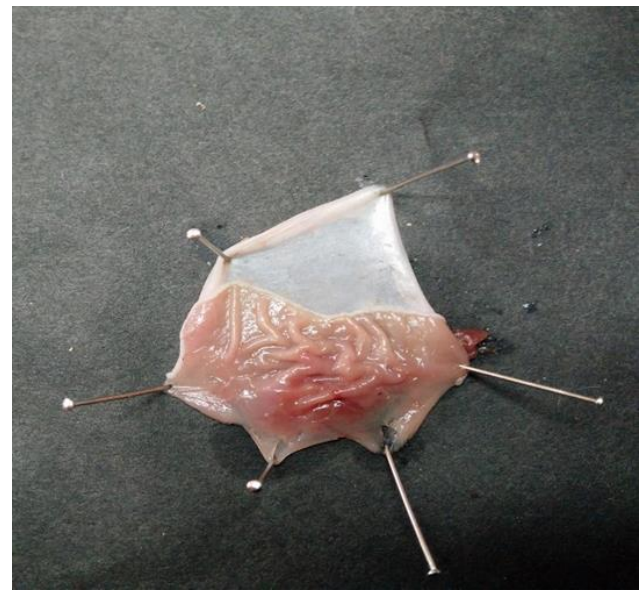

LDME 100

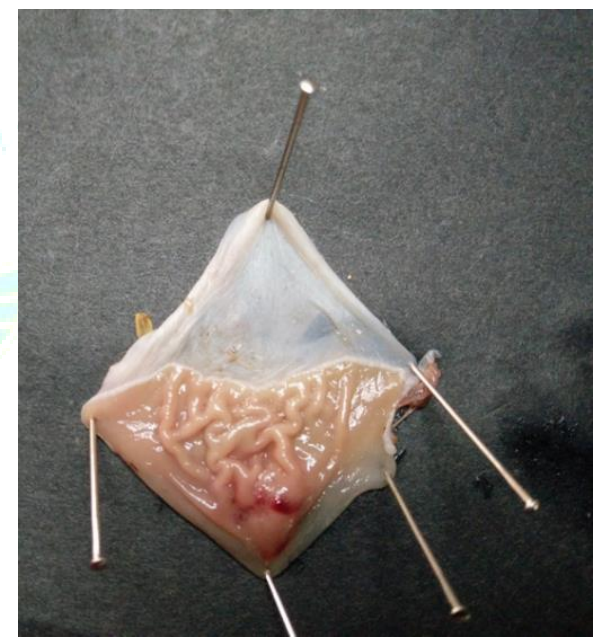

LDME 400

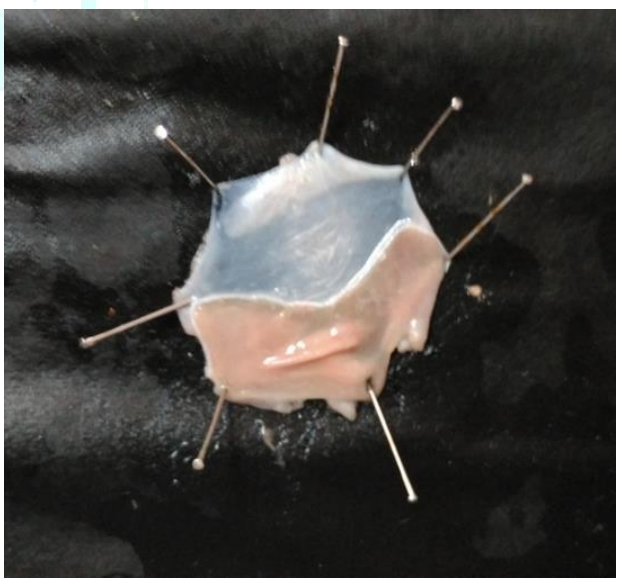

Figure 6: Ulcers of stomach in pylorus ligated rats 


\section{Ethanol induced ulcers}

\section{Normal}

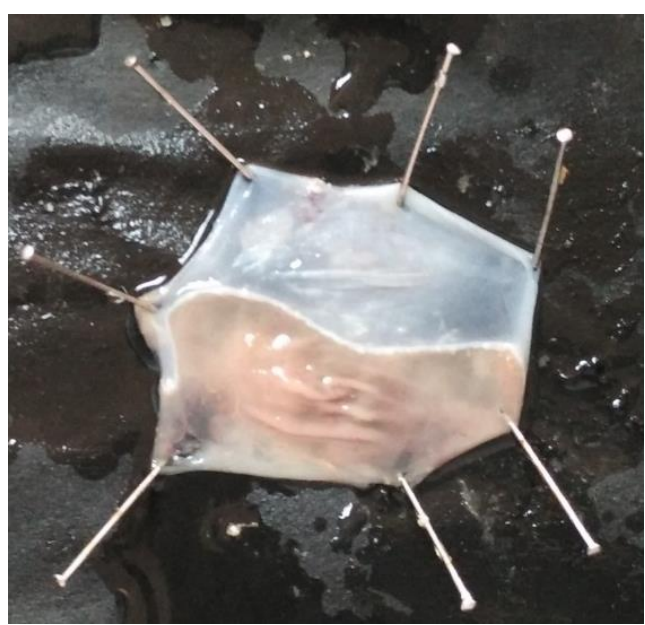

Standard

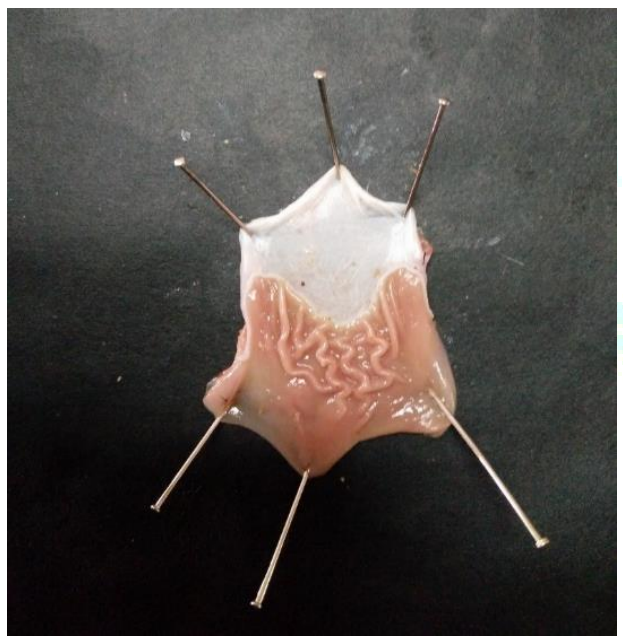

LDME 200

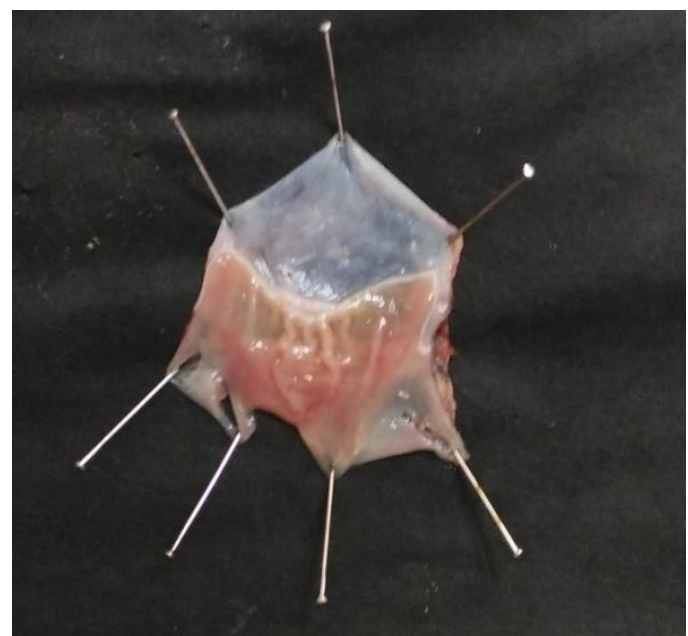

\section{Control}

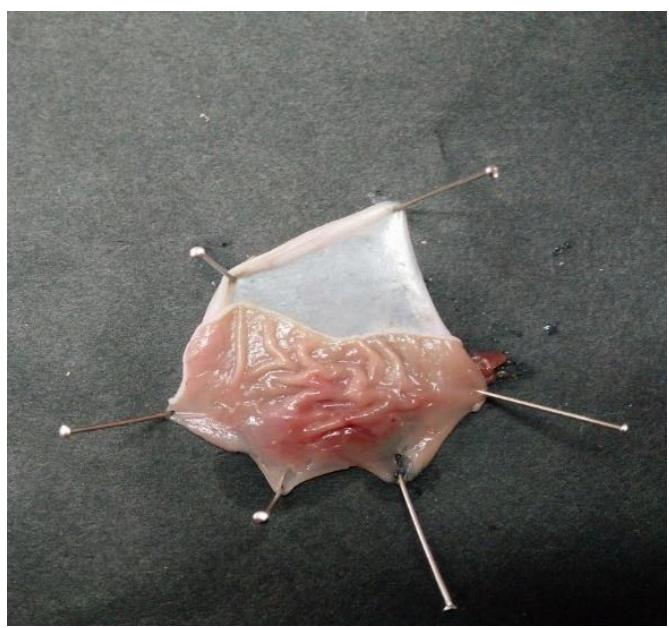

LDME 100

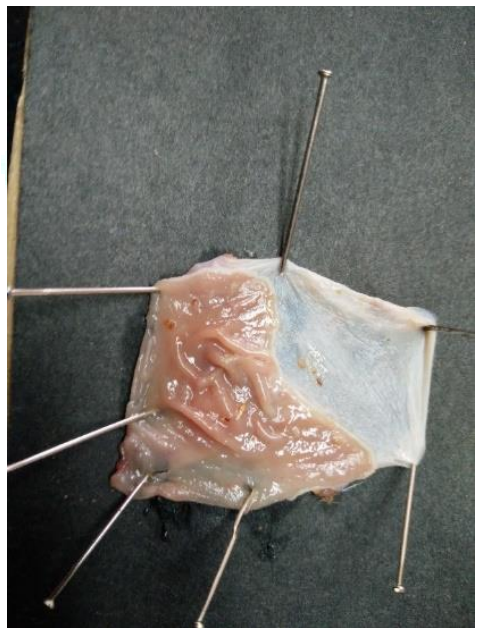

LDME 400

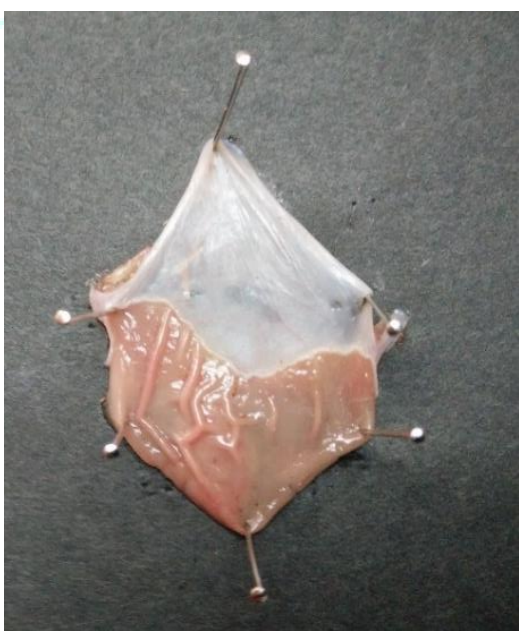

Figure 7: Ulcers of stomach in ethanol treated rats

\section{DISCUSSION}

Isolation of pure, pharmacologically active constituents from plants remains a long and tedious process. For this reason, it is necessary to have methods available which eliminate unnecessary separation procedures. Chemical screening is thus performed to allow localization and targeted isolation of new or useful constituents with potential activities. This procedure enables recognition of known metabolites in extracts or at the earliest stages of separation and is thus economically very important. Flavonoids, (a large group of naturally occurring plant polyphenolic compounds including flavones, flavonols, isoflavones, flavonones and chalcones), also known as nature's tender drugs, possess numerous 
biological and/or pharmacological activities. Recent reports of antiviral, anti-fungal, antioxidant, anti-inflammatory, antiallergenic, antithrombic, anticarcinogenic, hepatoprotective, and cytotoxic activities of flavonoids have generated interest in studies of flavonoid-containing plants. Flavonoids have demonstrated to exert beneficial effects on some diseases involving lipid peroxidation. The capability to interact with protein phosphorylation and the antioxidant, iron-chelating, and free radical scavenging activity may account for the wide pharmacological profile of flavonoids. [59-61]

Antioxidants that scavenge free radicals play an important role in cardiovascular disease, aging, cancer, and inflammatory disorders [54]. In addition, these naturally occurring antioxidants can be formulated to give nutraceuticals, which can help to prevent oxidative damage from occurring in the body. The extract was screened for its potential antioxidant activities using tests such as hydroxyl radical-scavenging activity, reducing power activity, and hydrogen peroxide-scavenging activity. The in-vitro antioxidant assay showed Leucas diffusa methanolic extract possess potent antioxidant activity when compared with reference compound ascorbic acid. Leucas diffusa could be useful for preparation of nutraceuticals as potent antioxidant to treat various human diseases and its complications.

The plant Leucas diffusa is widely distributed in India and Srilanka. The methanolic extract of aerial parts of the plant have been never studied. Hence the objective of the study is determining this effect from the methanolic extract Leucas diffusa. The preliminary phytochemical screening of whole plant extracts indicate in presence of flavonoid, alkaloid, tannins, terpenoids and glycosides may accounts antioxidant and anti-ulcer potential.

The antiulcer effect is screened in methanolic extract of Leucas diffusa on ethanol induced and pylorus ligated time and dose dependent ulcer study. The results get from these study have been shown that methanolic extract of Leucas diffusa produce antiulcer effect in ethanol induced and pylorus ligated ulcer models. In ethanol induced and pylorus ligated model, there is reduction in ulcer index, total acidity, $\mathrm{pH}$ of gastric secretion they compared with control treated group.

Pantoprazole used as a standard comparison agents. pantoprazole used as proton pump inhibitors blocker, is significantly reduce about $90 \%$ of basal, food induced and hormonal mediated gastric acid, which again induced by gastrin, parasympathomimetic drugs and Total acidity responsible quantification acid is present in the gastric secretion. It has an important aggressive factor which induced the ulcer. Gastric release is maintained by vagal control and higher activity of vagus stimulation also contributes to ulcer formation.

On ethanol administration, the mucosal mast cells mediate to secretion of vasoactive mediators containing histamine. Histamine is mediated to stimulate the synthesis of cyclic AMP through activation of the enzyme adenyl cyclase which mediate the activation of gastric proton pump and secrete of hydrogen ions. The treatment of methanol extract showed reduced levels of total acidity of the gastric contents.

Increased $\mathrm{pH}$ shows a lower concentration of the hydrogen ion. The hydrogen ion is a major triggering factor responsible for the etiologic factor for ulcer and gastric damage. LDME treatment indicate higher concentration of $\mathrm{pH}$ of the gastric juices. This values directly shown the LDME reduce possibility of ulcer and has a protective effect of surface of the gastric mucosa.

\section{CONCLUSION}

The present study indicates that the LDME have got profound antioxidant effect and showed significant anti-ulcer activity at higher dose. This may be due to presence of flavanoids in the methanolic extract. This novel finding will aid us to conduct bioactivity guided isolation and characterization of leading compounds in due course.

\section{REFERENCES}

1. Burks TF. Principles of Pharmacology. United States of America: International Thomson publishing Inc; 1995. p. 1063.

2. Kumar V, Abbas KA, Fausto N. Robbins and Cotran Pathologic Basis of Disease. 7th ed. New Delhi: Elsevier Inc; 2004. p. 817.

3. Peptic ulcer diagram. Available from:www.wanderiner.blogspot.com

4. Allison MC, Howatson AG, Caroline MG.Gastrointestinal damage associated with the use of nonsteriodal antiinflammatory drugs. N Engl J Med 1992; 327: 749-54.

5. Lenz HJ, Ferrari-Taylor J, Isenberg JI. Wine and five percent ethanol are potent stimulants of gastric acid secretion in humans. Gastroenterology 1983; 85: 1082-7.

6. Cohen S, Booth GH Jr. Gastric acid secretion and loweresophageal - sphincter pressure in response to coffee and caffeine. N Engl J Med 1975; 293: 897-9.

7. Feldman EJ, Isenberg JI, Grossman MI. Gastric acid and gastrin response to decaffeinated coffee and a peptone meal. JAMA 1981; 246: 248-50.

8. Shakeel Ahmad Jatoi, Akira Kikuchi, Dawood Ahmad, Kazuo N. Watanabe, Characterization of The Genetic Structure of Mango Ginger (Curcuma Amada Roxb.) From Myanmar in Farm and Genebank Collection by The Neutral And Functional Genomic Markers, Electronic Journal Of Biotechnology Issn: 0717-3458.

9. ANTIOXIDANT ACTIVITY OF LEUCAS ASPERA, B. K. Das*, B. Das, F. K. Arpita, M. A. Morshed, A. Uddin, R. Bhattacherjee , J.M.A. Hannan , IJPSR, 1; Vol. 2(7): 1746-175, June 2011.

10. Phytochemical and Pharmacological investigation of an indigenous medicinal plant Leucas aspera ,V.N. Kalpana, V. Devi Rajeswari, International Journal of PharmTech Research,9(8), pp 399-407, 2016

11. Tahareen S, Shwetha R, Myrene RD. Potential antioxidant, anti-inflammatory and antibacterial evaluation of extracts of leucas aspera using in vitro models. Int J Pharm Pharm Sci;8(11):292-297, 2016.

12. K. Atchutkumar, T.Satyanarayana, K.Raj kiran , k.rajesh , antihyperglycemic activity of methanolic extract of leucas aspera wild whole plant on blood glucose levels of streptozotocin-induced diabetic rats Int J Pharm Sci, Vol 5, Suppl 2, 76-78, FEB 2013.

13. Ramachandran Somasundaram , Priyanka Vaddadi, Dhanaraju Magharla Dasaratha, Anti-Oxidant Potential and Antiinflammatory activity of Leucas Diffusa Plant Extract, Int J Pharm 2013; 3(4): 819-829. 